RNA-Protein-Wechselwirkung

\title{
Systemweite Anreicherung von RNA-Protein-Komplexen
}

STEFAN PFISTER, BENEDIKT M. BECKMANN

HU BERLIN, IRI LIFE SCIENCES

RNA-protein complexes (RNPs) are key players in cell physiology, especially in the context of RNA metabolism. However, their analysis has been dependent on specific protein epitopes or RNA sequence elements, preventing unbiased and cell-wide studies. We developed a three-step protocol, termed Phenol Toluol extraction (PTex), to isolate the complete suite of RNPs in cells, solely based on their unique physicochemical properties after UV-cross-linking. PTex, along with other recently developed unbiased techniques, has the potential to guide the way to cell-wide analysis of RNA-protein interactions.

DOI: $10.1007 / \mathrm{s} 12268-020-1465-4$ (C) Die Autoren 2020

- Für die zelluläre Genregulation sind Wechselwirkungen zwischen Ribonukleinsäuren (RNAs) und Proteinen essenziell. Vor allem die Rolle von RNA-Bindeproteinen (RBPs) - also Proteinen, die mit RNA interagieren - rückte in den letzten Jahren immer stärker in den Fokus. RBPs erfüllen zentrale Funktionen in der posttranskriptionellen Regulation sowie in der Genexpression, indem sie an Mechanismen wie Modifikation, Transport, Translation oder Abbau der RNA beteiligt sind.

Dabei wurden neue Methoden entwickelt, die sich nicht auf einzelne RNA-Proteinkomplexe (Ribonukleoproteinkomplexe, RNPs) konzentrieren, sondern die Identifikation von RNA-Protein-Wechselwirkungen zellweit ermöglichen. Hunderte Proteine mit bislang unbekannter RNA-Bindeaktivität wurden somit gefunden $[1,2]$.

\section{Systemweite RNA-Protein-Analytik}

Anders als bei Transkriptionsfaktoren oder anderen DNA-Bindeproteinen sind die Interaktionen zwischen RNA und Proteinen oft vorübergehend und hochdynamisch, sodass ein einzelnes RNA-Molekül von der Transkription bis zum Abbau mit einem ganzen Netzwerk aus RBPs wechselwirkt [3]. Eine oft verwendete Technik, um diese Interaktionen für eine Analyse zu stabilisieren, ist ein initiales Cross-Linking durch UV-Licht (irreversibel) oder Formaldehyd (reversibel), das RNA und Protein über eine kovalente Bindung vernetzt und stringente Aufreinigungsprotokolle ermöglicht. Dies schaffte die Voraussetzungen für Methoden wie CLIP (cross-linking and immunoprecipitation), bei der RNAs, die an ein einzelnes Protein gebundenen sind, durch RNA-Sequenzierung systemweit identifiziert werden können. Im Rahmen des ENCODE-Projekts wurde dies für mehr als 350 RBPs systematisch durchgeführt [4]. Die Identifikation von neuen RBPs hingegen ist in den letzten Jahren hauptsächlich auf die RIC $(R N A$ interactome capture)-Technik zurückzuführen. Hierbei können nach Anreicherung von mRNA die daran gebundenen Proteine durch Massenspektrometrie bestimmt werden [2].

Die genannten Methoden haben allerdings Einschränkungen. So benötigt der CLIPAnsatz einen vorhandenen Antikörper, der die spezifische Aufreinigung eines einzelnen Proteins und dessen gebundener RNA ermöglicht. Die RIC-Methode hingegen ist nur nur für polyadenylierte (eukaryotische) mRNA anwendbar, da eine Anreicherung dieser Transkripte und der daran gebundenen RBPs über Oligo-(dT)-Beads erfolgt. Andere RNAKlassen wie rRNA, tRNA, prä-mRNAs und einige ncRNAs lassen sich somit nicht analysieren; von prokaryotischen RNPs ganz abgesehen.
PTex: Flüssig-Flüssig-Extraktion reichert RNA-Protein-Komplexen an

Eine andere Herangehensweise besteht darin, möglichst alle zellulären Komplexe aus RNA und Protein biochemisch anzureichern. Die Selektion der Komplexe erfolgt dabei nicht über spezifische Merkmale wie Proteinepitope oder Nukleinsäuresequenzen, sondern über die physikalisch-chemischen Eigenschaften von RNPs, die sie vom Rest der zellulären Moleküle unterscheiden.

Wir haben dazu ein etabliertes Protokoll zur Anreicherung von RNA modifiziert: die Phenolextraktion. Bei der Phenolextraktion von Zellmaterial reichert sich RNA bei niedrigem pH-Wert in der oberen, wässrigen Phase an, während sich Proteine in der unteren, organischen Phenolphase wiederfinden. Die durch UV-Licht gecrosslinkten RNPs stellen ein Hybrid aus beiden Molekülklassen dar, das es in dieser Form in der Zelle nicht gibt. RNA-Proteinkomplexe sammeln sich an der Phasengrenze (Interphase). Diese neue Methode, PTex (Phenol Toluol extraction, Abb. 1), ermöglicht es daher, alle RNPs aus diversen Probenmaterialien ohne Antikörper oder komplementäre Nukleinsäuresequenzen von anderen ungebundenen RNAs oder Proteinen $\mathrm{zu}$ trennen und anzureichern [5, 6]. Die einzigen Voraussetzungen für PTex bestehen darin, dass das Ausgangsmaterial mit UV-Licht effizient bestrahlt wird und danach ohne Zugabe von denaturierenden Reagenzien lysiert werden kann. Auf diese Weise konnten wir RNPs aus humaner Zellkultur, Mausgewebe und auch Bakterien direkt extrahieren und RNA-Bindeproteine durch Massenspektrometrie identifizieren [5].

Neue Methoden zur Analyse von RNAProtein-Wechselwirkungen

Das Spektrum an verfügbaren Methoden zur Untersuchung von RNA-Protein-Interaktionen hat sich in den letzten Jahren erheblich verbreitert. Zeitgleich mit unserer PTexMethode wurden zwei weitere Protokolle vorgestellt, die RNPs durch Flüssig-FlüssigExtraktion mit Phenol anreichern (OOPS, 
- Abb. 1: Die Phenol-ToluolExtraktion (PTex). A, Im ersten Schritt der PTex-Methode wird lysiertes Probenmaterial mit Phenol und Toluol (im Verhältnis 50:50) bei neutralem $\mathrm{pH}$-Wert gemischt und zentrifugiert. Es kommt zur Phasentrennung: RNA, Proteine und RNA-Proteinkomplexe reichern sich in der oberen, wässrigen Phase an, während DNA und Lipide in der Interphase verbleiben. Die wässrige Phase wird abgenommen und im zweiten Schritt unter denaturierenden und chaotropen Konditionen bei niedrigem $\mathrm{pH}$ Wert mit Phenol gemischt [7]. Hier trennen sich die verbliebenen drei Molekülklassen so auf, dass sich die freie RNA in der oberen, wässrigen Phase, die freien Proteine in der unteren, organischen Phase und die RNAProteinkomplexe an der Phasengrenze (Interphase) anreichern. Mit der Interphase wird dieser Schritt wiederholt, um Hintergrundkontaminationen mit freier RNA bzw. freien Proteinen zu reduzieren. Insgesamt dauert das Protokoll etwa drei Stunden. B, Western Blot zur Aufreinigung des RNA-Bindeproteins HuR direkt aus Mausgewebe (Hirn). Das durch PTex isolierte HuR (im Komplex mit RNA nach UVCross-Link) wird durch RNase verdaut, bevor es nahe seiner molekularen Masse (35 kDa) durch das Gel migriert. ACTB: Actin-Kontrolle. Abbildung modifiziert nach [5], CC-BY 4.0.

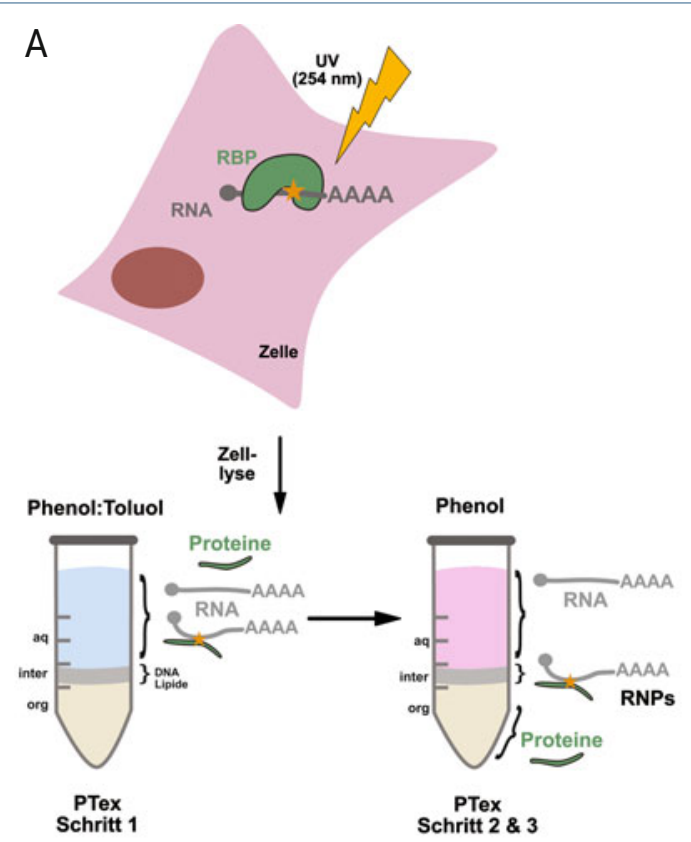

B

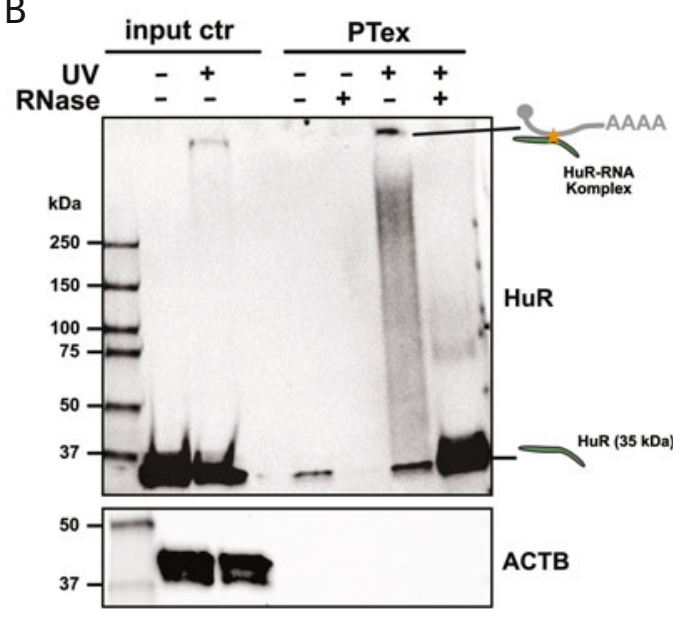

XRNAX) [8]. Zwei andere Ansätze (2C, TRAPP) nutzen eine Festphase zur Anreicherung von RNPs durch Bindung von SilicaBeads an Nukleinsäuren [9], während die Techniken R-deep, DIF-FRAC und GradR auf einer Ultrazentrifugation mit Dichtegradienten als Prinzip zur Anreicherung von Komplexen basieren [10]. Wie PTex nutzen alle diese Methoden grundlegende physikalische oder chemische Unterschiede zwischen RNP und freier RNA bzw. Proteinen und ermöglichen es dadurch, prinzipiell alle RNA-Proteinkomplexe einer Zelle zu untersuchen. Während es diese Methoden nun erlauben, RNPs aus diversen Quellen unspezifisch zu isolieren, sollte nicht vergessen werden, dass über 90 Prozent der zellulären RNA aus ribosomaler RNA besteht. Ohne weitere Bearbeitung bestehen die so aufgereinigten Proben also zu einem nicht unerheblichen Teil aus rRNA und ribosomalen Proteinen.

Neben der optimierten Isolierung von RNPs ist auch die Fortentwicklung der Analyse zur Lokalisierung des UV-induzierten Cross-Links ein wichtiger Schritt zum Verständnis von RNA-Protein-Wechselwirkungen. Über die Isolierung von RNPs hinaus kann dadurch die Bindestelle zwischen RNA und Protein exakter bestimmt werden. Dies gestaltet sich allerdings schwierig, da der Cross-Link durch Bestrahlung mit UV-Licht als kovalente Bindung irreversibel ist. Daher bleibt selbst nach proteolytischem und nukleolytischem Enzymverdau ein Peptid mit einem heterogenen RNA-Rest übrig (Abb. 2).

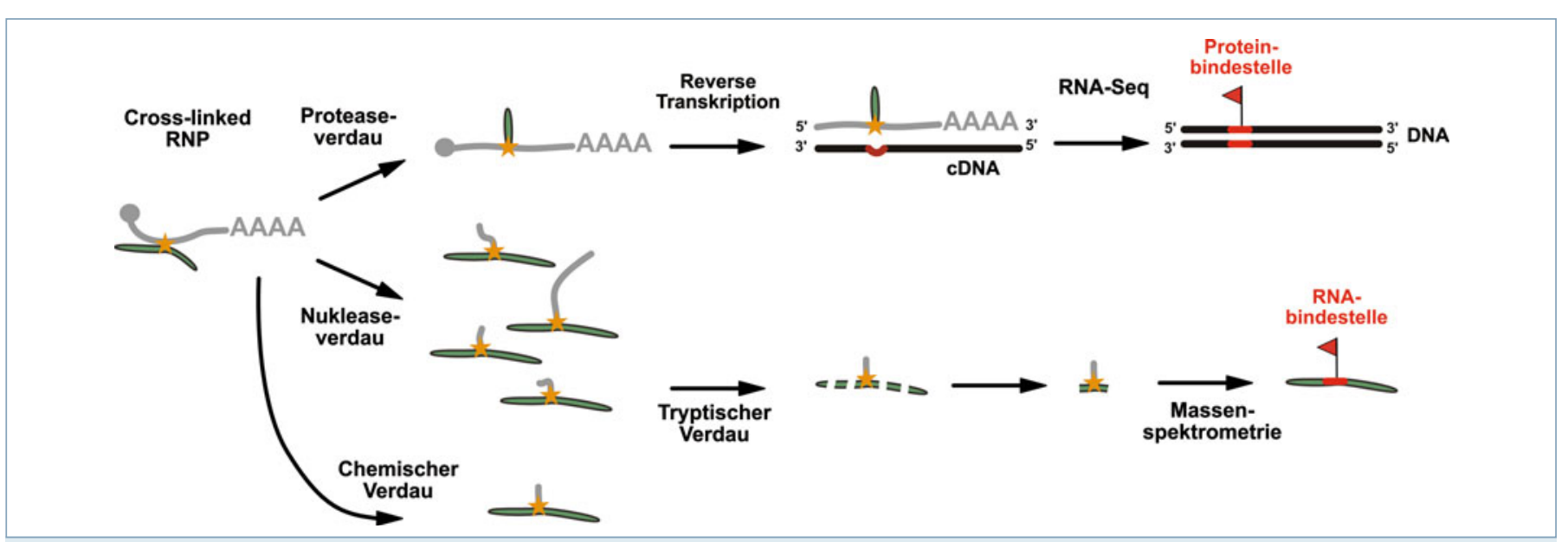

$\triangle$ Abb. 2: Lokalisierung der RNA-Protein-Interaktionsstelle. Der Cross-Link kann genutzt werden, um die Proteinbindestelle in RNA zu detektieren. Bei der cDNA-Synthese erzeugt der gebundene Peptidrest charakteristische Mutationen, die nach der Sequenzierung der DNA die Bindestelle des Proteins im ursprünglichen RNA-Transkript anzeigen. Die Identifikation der RNA-Bindestelle in Proteinen ist komplexer: Ein enzymatischer Verdau erzeugt heterogene RNA-Reste. Daher werden spezielle Protokolle und Analysen benötigt $[9,11]$, um die RNA-Bindestelle zu identifizieren. Ein chemischer Abbau durch z. B. Flusssäure [12] erzeugt homogene RNA-Reste; solche Peptide können durch Massenspektrometrie leichter detektiert werden. 
In CLIP-Experimenten ist dies jedoch ein Vorteil: Bei der reversen Transkription zur Erstellung der DNA-Sequenz-Libraries wird an der Stelle des Cross-Links ein charakteristischer Fehler in die cDNA eingebaut. Diese Mutation kann dann gezielt während der bioinformatischen Analyse gesucht werden und damit die Stelle anzeigen, an der das Protein auf der RNA gebunden hat. Für massenspektrometrische Untersuchungen hingegen ist der gebundene RNA-Rest ein Problem. Die zusätzlichen kovalent gebundenen Nukleotide erlauben nicht, das gecrosslinkte Peptid über seine Masse direkt zu identifizieren. Erste Ansätze bestanden daher darin, die Massen vieler möglicher RNA-Addukte als potenzielle Peptidmasse zu berechnen oder Peptide nahe der Bindestelle zu finden [2, 11]. Auch hier scheint jetzt ein Durchbruch gelungen: Anstelle eines enzymatischen Verdaus mit unterschiedlichen Nukleotidresten kann die gebundene RNA chemisch durch Flusssäure abgebaut werden, was homogene Mononukleotide an der Bindestelle zurücklässt. Dies ermöglicht nun eine systemweite Identifikation von RNA-Bindestellen innerhalb von Proteinen [12]. Extraktionsverfahren wie PTex bieten sich hier als initiales Aufreinigungsverfahren an [5].

PTex und die anderen neu entwickelten Methoden werden zurzeit verfeinert und miteinander kombiniert [9], sodass mit weiteren Fortschritten in der Analyse von RNA-Protein-Interaktionen gerechnet werden kann.

\section{Danksagung}

Unsere Arbeit zu RNA-Protein-Wechselwirkungen wird finanziert durch die DFG (IRTG 2290) und das „Plus 3“ Programm der Boehringer Ingelheim Stiftung (BIS).

\section{Literatur}

[1] Beckmann BM, Horos R, Fischer B et al. (2015) The RNAbinding proteomes from yeast to man harbour conserved enigmRBPs. Nat Commun 6:10127

[2] Hentze MW, Castello A, Schwarzl T et al. (2018) A brave new world of RNA-binding proteins. Nat Rev Mol Cell Biol 19:327-341

[3] Gehring NH, Wahle E, Fischer U (2017) Deciphering the mRNP code: RNA-bound determinants of post-transcriptional gene regulation. Trends Biochem Sci 42:369-382

[4] Van Nostrand EL, Freese P, Pratt GA et al. (2020) A largescale binding and functional map of human RNA-binding proteins. Nature 583:711-719

[5] Urdaneta EC, Vieira-Vieira CH, Hick T et al. (2019) Purification of cross-linked RNA-protein complexes by phenol-toluol extraction. Nat Commun 10:990

[6] Urdaneta EC, Beckmann BM (2020) Fast and unbiased purification of RNA-protein complexes after UV cross-linking. Methods 178:72-82

[7] Chomczynski P, Sacchi N (1987) Single-step method of RNA isolation by acid guanidinium thiocyanate-phenol-chloroform extraction. Anal Biochem 162:156-159

[8] Smith T, Villanueva E, Queiroz RML et al. (2020) Organic phase separation opens up new opportunities to interrogate the RNA-binding proteome. Curr Opin Chem Biol 54:70-75 [9] Van Ende R, Balzarini S, Geuten K (2020) Single and combined methods to specifically or bulk-purify RNA-protein complexes. Biomolecules 10:E1160

[10] Caudron-Herger M, Rusin SF, Adamo ME et al. (2019) R-DeeP: Proteome-wide and quantitative identification of RNA-dependent proteins by density gradient ultracentrifugation. Mol Cell 75:184-199
[11] Kramer K, Sachsenberg T, Beckmann BM et al. (2014) Photo-cross-linking and high-resolution mass spectrometry for assignment of RNA-binding sites in RNA-binding proteins. Nat Methods 11:1064-1070

[12] Bae JW, Kwon SC, Na Y et al. (2020) Chemical RNA digestion enables robust RNA-binding site mapping at single amino acid resolution. Nat Struct Mol Biol 27:678-682

Funding Open Access funding enabled and organized by Projekt DEAL. Open Access Dieser Artikel wird unter der Creative Commons Namensnennung 4.0 International Lizenz veröffentlicht, welche die Nutzung, Vervielfältigung erlaubt, sofern Sie den/die ursprünglichen Autor(en) und die Quelle ordnungsgemäß nennen, einen Link zur Creative Commons Lizenz beifügen und angeben, ob Änderungen vorgenommen wurden. Die in diesem Artikel enthaltenen Bilder und sonstiges Drittmaterial unterliegen ebenfalls der genannten Creative Commons Lizenz, sofern sich aus der Abbildungslegend nichts anderes ergibt. Sofern das betreffende Material nicht unter der genannten Creative Commons Lizenz steht und die betreffende Handlung nich Wech gesetzlichen Vorschriften erlaubt ist, ist fur die oben aufgefuhrten Weiterverwendungen des Materials die Einwilligung des jeweiligen Lizenzinformation auf http //creativecommons org/licenses/by/4. /deed de.

Korrespondenzadresse:

Dr. Benedikt Beckmann

IRI Life Sciences

Humboldt-Universität zu Berlin

Philippstraße 13

D-10115 Berlin

benedikt.beckmann@iri-lifesciences.de

www.beckmannlab.de

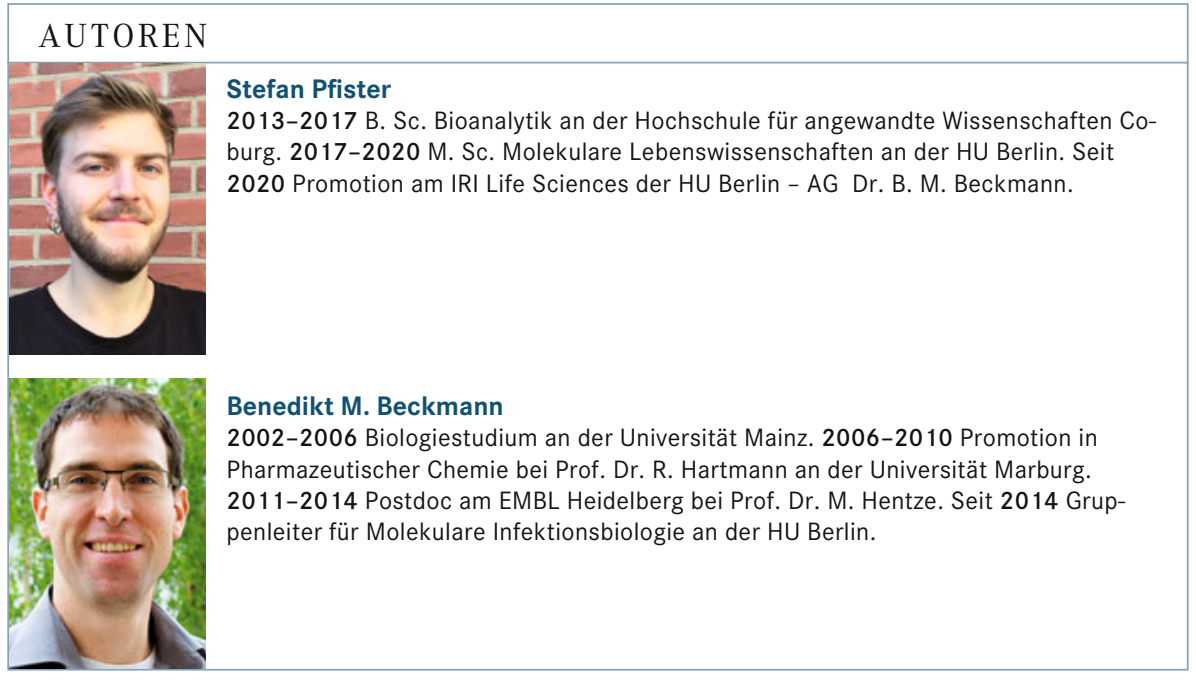

